\title{
LA ORGANIZACION POLITICA Y ADMINISTRATIVA DE BOGOTA Y DE OTTAWA-HULL
}

\author{
POR \\ JaIME Vidal PeRdomo
}

SUMARIO: I. Ottawa-Hull como capital del Canadá y las propuestas de distrito federal.-II. La evolución organizativa de Bogotá.

Puede parecer a primera vista extraño reunir en un solo trabajo los rasgos fundamentales de la organización político-administrativa de las capitales de Colombia y el Canadá. Los dos países son muy distintos, la vida y la estructura de las dos ciudades también lo son.

La escogencia de Bogotá, capital de Colombia, obedece a la circuntancia de haber vivido en ella y participado en la discusión de su esquema político-administrativo. En cuanto a la segunda, capital del Canadá, desempeño un cargo diplomático alli y he comenzado a estudiar sus instituciones y la manera como ellas han venido evolucionando a través del tiempo.

Es frecuente en el derecho constitucional y administrativo utilizar enfoques comparativos. Lo hacemos mucho los profesores latinoamericanos, mirando hacia las instituciones de España, Francia, Italia, Alemania, Estados Unidos, Gran Bretaña, preferencialmente. Mi permanencia en el Canadá me ha permitido apreciar el interés que el derecho de esta gran nación, de cultura jurídica anglosajona y francesa a la vez, puede ofrecer para los estudios comparativos.

Por lo demás, el tema del gobierno de las ciudades capitales es eminentemente comparativo. Es indudable que la manera como se dispuso a la ciudad de Washington como la capital federal de los Estados Unidos de América ha servido de modelo para, seguirlo o separarse de él, en los países bajo forma federal. Otro aspecto de los problemas organizativos de las grandes ciudades, el de las áreas metropolitanas, no se estudia independientemente en cada país, sino tomando en cuenta el fenómeno de expansión de esas ciudades sobre los municipios circunvecinos ocurrido en otras latitudes.

Por ejemplo, en Colombia el tema de las áreas metropolitanas, introducido en la reforma constitucional de 1968, ha estado influido por la literatura jurídico-administrativa española de la materia.

Debo cerrar esta introducción diciendo que la perspectiva comparativa que este ensayo quiere tomar puede servir de referen- 
cia para el estudio de las fórmulas de organización política y administrativa que se necesitan en Bogotá. Ellas han girado en torno de las alternativas «Bogotá como distrito capital», según un modelo federalista, o «Bogotá como área metropolitana».

Esta discusión ya lleva varios años en mi país; la experiencia del Canadá, en la búsqueda de una ciudad capital federal, propuesta por unos y rechazada por otros, de un lado, $y$, del otro, el funcionamiento práctico de «áreas metropolitanas», alrededor de las ciudades de Ottawa y Hull, puede ser muy ilustrativo para Colombia.

\section{OTTAWA-HULL COMO CAPITAL DEL CANADA $Y$ LAS PROPUESTAS DE DISTRITO FEDERAL}

Debe indicarse previamente que dentro de la organización federal del Canadá, que proviene del Acto Constitucional de 1867 , las dos ciudades mencionadas pertenecen a dos provincias distintas, en su orden la de Ontario y la de Quebec.

Fuera de esto, que dentro del encuentro histórico pugnaz que tuvieron Inglaterra y Francia en el territorio americano, es en el Canadá precisamente donde se marca con mayor fuerza el contraste entre las dos culturas. Ottawa y Hull están separadas apenas físicamente por el río que lleva el nombre de la primera ciudad, forman parte de la capital del Canadá, pero representan valores culturales y lingüísticos diferentes. Toda esta confrontación, larga en el tiempo, ha estado presente en el debate de las fórmulas que se han elaborado sobre la capital de la nación.

a) El nombre de Ottawa, que lo lleva también el río que la baña por el norte, procede de los indígenas que habitaban la región y que eran intermediarios en el comercio de las pieles que se llevaban al Quebec para la venta en la costa oriental del Canadá (1).

El paisaje que rodea la ciudad es muy bello: en 1613 Samuel Champlain, el gran conquistador del territorio de la provincia del Quebec, se maravillaba de la belleza del emplazamiento de la que sería la capital del Canadá. Otros asentamientos -como los de los colonos que vinieron de los Estados Unidos en 1800-, que tambien tuvieron en cuenta las caídas de agua y las posibilidades de energía y la riqueza forestal, se hicieron al otro lado del río, en la que hoy es la ciudad de Hull, de la provincia de Quebec, y no en Ontario, donde está Ottawa.

(1) Véase National Capital Commission: A Capital in the Meking, Ottawa, 1984, p. 8. Esta publicación, en inglés y francés, contiene los principales aspectos sobre el tema. 
b) Esta última fue seleccionada como capital del Canadá por la Reina Victoria en 1857, cuando ese título se lo disputaba con Quebec City, Montreal, Toronto y Kingston.

Distintas razones tuvo la soberana inglesa al hacer la escogencia. Fuera de la belleza del lugar, existía ya el canal Rideau para unir a Montreal y el oeste del país evitando el río San Lorenzo, que podía caer en poder de los americanos, con quienes había habido una guerra en 1812. La colocación de la ciudad en el límite de dos provincias de diferente cultura, su condición de punto intermedio entre Quebec y Toronto, y la existencia de terrenos públicos adquiridos para futuros edificios gubernamentales, facilitaron la designación.

Al ponerse en marcha la confederación, en 1867, bajo la forma constitucional federal que hoy día tiene el Canadá, The Constitution Act de esta fecha, expedido por el Parlamento británico, expresó en su artículo 16 que mientras la Reina no decidiera otra cosa la sede del Gobierno del Canadá sería Ottawa.

En 1982, bajo el impulso del gobierno del Primer Ministro Pierre Trudeau, y en disputa con la provincia de Quebec, que no aceptó el acto constitucional, se produjo la denominada "repatriación» de la Constitución. Por ésta el Parlamento Británico renunció a legislar en adelante sobre el Canadá. No se dispuso nada sobre Ottawa como capital. Tampoco hay ninguna previsión sobre este particular en el Meach Lake Accord, nombre que se da a la reforma constitucional que está en trámite impulsada por el gobierno de Brian Mulroney.

En ese carácter de capital en Ottawa tienen su sede tanto el Gobernador general (quien ejerce su autoridad a nombre de la Reina de Inglaterra), como el Parlamento (Cámara de los Comunes y Senado), el Primer Ministro y su gabinete, y la Corte Suprema del Canadá.

c) En el British North American Act de 1867 también se señalaron las capitales de las cuatro provincias que integraron la Confederación canadiense (las otras seis se han incorporado después). Entre ellas la de Ontario, que es Toronto, y la de la provincia de Quebec, que es la ciudad del mismo nombre.

Según Wilfrid Eggleston (2), estas normas constitucionales han tenido consecuencias para la organización de la capital. Ottawa dejó de ser capital provincial, pero como capital nacional o federal, digamos, nuevamente quedó situada dentro de una provincia, y el

(2) Citado por Douglas H. FULLERTON: The Capital of Canadá. How should it be governed?, Ottawa, 1974, vol. 2, p. 10. Es el más completo estudio de la organización de la capital del Canadá. 
río del mismo nombre se convirtió en límite de dos gobiernos bastante autónomos, el de Ontario y el de Quebec.

Sustraer a Ottawa-Hull del régimen municipal determinado por la legislación de las dos provincias ha sido una dificultad hasta ahora insuperable para quienes han sostenido la necesidad de erigir su territorio en distrito federal.

No obstante este principio constitucional del derecho canadiense, de subordinación de lo municipal al régimen legal dictado por las provincias (las partes integrantes el Estado federal), ha podido crearse por ley federal de 1958 una autoridad nacional, justamente la National Capital Commission.

Aunque los poderes de esta autoridad administrativa son limitados, están principalmente dirigidos hacia la planificación de la capital. La utilización del instrumento de la compra o de la expropiación va en ese sentido.

Desde el punto de vista constitucional, la decisión de la Corte Suprema del Canadá en el caso Munro (3) ha sido calificada como de mucha importancia. Al declarar válida en 1965 una expropiación hecha por la National Capital Comission de los terrenos del señor Munro destinados al cinturón verde alrededor de Ottawa, la Corte rechazó que la materia de la planificación fuera una competencia provincial.

El señor Fulleton, antiguo director de la National Capital Commission, al comentar la doctrina de la sentencia de la Corte Suprema del Canadá, conformada por cierto por otra de 1966, advierte (4) en el libro citado que es una decisión fundamental, pues reconoce a la Federación unos poderes jurídicos en asuntos que se creían del exclusivo resorte municipal, Así, el Gobierno Federal quedó vinculado a la construcción de la capital del Canadá a través de la Comisión.

d) Este breve esbozo jurídico nos muestra la existencia de una autoridad federal, la National Capital Commission, con unas facultades para regular el crecimiento de la capital alrededor de las ciudades de Ottawa y Hull. Pero a las dos ciudades, también, sometidas al régimen de autoridades y competencias municipales determinado por la legislación de las dos provincias vecinas.

No obstante, las ideas de la capital federal (o distrito federal), ligadas a los países del modelo federalista (piénsese en Washington, Camberra, Ciudad de México, Brasilia, Caracas, Nueva Delhi, Buenos Aires, para dar algunos ejemplos), florecieron al paso del desarrollo del Canadá.

(3) Véase Douglas H. Fullerton: Op. cit., vol. 2, p. 247, donde aparece el texto de la sentencia de la Corte.

(4) Obra citada, vol. I, p. 13. 
Según el documento de la National Capital Commission ya citado, sir Wilfred Laurier, quien fue Primer Ministro, decía en 1896 que él quería hacer de Ottawa la Washington del Norte y el centro intelectual de la nación. En ese año se creaba la Comisión de Mejoramiento de la Capital para embellecer a la ciudad, que si bien por edicto real tenía el más alto rango en el Canadá, estaba todavía vinculada en su aspecto físico a su condición de antiguo sitio militar y centro maderero.

La creación de un distrito federal aparece como propuesta en el Plan Holt de 1915. El estudio, dirigido por el señor Herbert S. Holt, estaba encaminado a presentar al Gobierno Federal iniciativas sobre la expansión y progreso de la ciudad, como lo han hecho otros a cuya cabeza han figurado personas eminentes. Dicho plan recomendaba una reforma política de mucha importancia en términos que vale la pena citar: «Estamos bien convenicdos que las mejoras futuras de los alrededores de la capital, en Ottawa y Hull, no deben ser emprendidas sino después del establecimiento de un distrito federal y la obtención por la autoridad federal de una cierta competencia en el dominio de la administración municipal».

Algunas otras recomendaciones, propias del denominado ahora derecho urbanístico, como las restricciones impuestas al derecho de propiedad en la construcción de edificios, y la zonificación para la distinción de sectores residenciales, también figuran en el informe Holt. Según la historia documental de la ciudad que se ha venido citando, las circunstancias de la primera guerra mundial y la participación del Canadá en ella no permitieron la operatividad del plan. Esto no impidió que más tarde buena parte de lo expresado en el plan Holt fuera puesto en marcha por otros urbanistas, como el desplazamiento de las vías férreas y la descentralización de edificios públicos federales hacia Hull.

En una informe posterior (Cauchon, 1922) también se propuso organizar un distrito federal; una comisión de Gobierno Federal estaría encargada del desarrollo y de los servicios en la región de la capital, pero respetando la autonomía provincial y municipal. Como se sabe, esta limitación es la que ha estado al origen de la creación de las áreas metropolitanas en otros lugares.

Otros estudios que más tarde se efectuaron contemplaron la necesidad de mejorar la coordinación de las autoridades que debían intervenir en el desarrollo de Ottawa, así como la construcción de parques y avenidas y el embellecimiento de sitios históricos.

La iniciativa de la organización política de la capital fue llevada en 1944 a un Comité conjunto de la Cámara de los Comunes y del Senado, así como los problemas fiscales de la ciudad de Ottawa 
debidos a las exenciones de las tierras del Gobierno Federal; sin embargo, la idea relativa a la organización del distrito federal no fue analizada, aunque se ampliaron las facultades de la Comisión que ha tenido a su cargo el estudio de medidas en la región capital y la realización de cierta obras.

En el año de 1945 un área de 2.330 kilómetros cuadrados repartidos más o menos igualmente en los dos lados del río Ottawa fue declarada "distrito de la capital nacional». De este modo el sector quebecquense en torno de la ciudad de Hull seguía ligado, como lo ordenaba la geografía, a la capital nacional que había nacido en la vecina Ottawa.

e) Al comienzo de la década de 1950 se publicaba en Ottawa el plan Greber (del nombre del arquitecto francés que estuvo de asesor) sobre el desarrollo de la ciudad. Dentro de él es de destacar la opinión según la cual no era indispensable el establecimiento del distrito federal para poner en marcha las recomendaciones; en su reemplazo era necesaria la coordinación de las autoridades de los diferentes niveles y una autoridad nacional de planeación.

Si bien este trabajo tiene una perspectiva institucional, debe hacerse notar la previsión que se ha tenido en cuanto al ensanche de la capital, factor que naturalmente contrasta con el crecimiento turbulento de las ciudades latinoamericanas. Prueba entre otras de aquella visión sobre el futuro urbanístico es la adquisición de las tierras para el parque de la Gatineau, en la provincia de Quebec, que tiene una extensión de 35.000 hectáreas, la mayor parte bajo control estatal y otra parte de propiedad privada.

Realizaciones como la indicada hacen de la capital una ciudad hermosa. Si bien desde sus comienzos estuvo regalada por la naturaleza, la mano del hombre ha venido en su apoyo, por ejemplo, con la construcción del canal Rideau, que en el invierno se convierte en una gigantesca pista de patinaje, y la potencialidad económica del Canadá le ha permitido ir fortaleciendo la silueta de capital. Esta, como lo entendía el anterior Director general de la National Capital Commission, señor lan A. Dewar, al introducir el libro documental de que he hecho uso, «es más que una ciudad y una sede del gobierno. Es el símbolo de la fuerza y unidad de un país, el hogar espiritual de su nacionalidad, y el rostro que ella muestra al mundo».

f) Según lo que firma Douglas $H$. Fullerton (5), ya en 1956 no se hizo en un informe legislativo mención del distrito federal en las recomendaciones. En cambio, en 1958 se expide la ley sobre la National Capital Commission extendiendo el territorio de la «región

(5) Obra citada, vol. I, p. 13. 
de la capital nacional» alrededor de Ottawa y Hull, según el documento de la National Capital Commission (6).

g) Muchos otros aspectos de la interesante evolución de la capital canadiense pudieran evocarse; entre ellos el de la discusión que parece haber aflorado sobre si se ajusta a la Constitución, que designa a Ottawa como capital, ella sola, que en la práctica lo sea el territorio que conforma la Región de la Capital Nacional (7). Sin embargo, se extendería demasiado el tamaño de esta comunicación.

Por ello debemos limitar los comentarios que siguen a los rasgos principales de la National Capital Commission a las áreas metropolitanas alrededor de Ottawa y Hull, y a la propuesta del profesor Donald C. Rowat sobre el distrito capital.

h) La Ley de 1958 (National Capital Act) determina la composición y las funciones de la Comisión. Se le quiere dar carácter nacional por el nombramiento que hace el Gobernador general en Consejo del Presidente y Vicepresidente de la misma y de los demás restantes 20 miembros. Hay, sin embargo, una representación de cada una de las diez provincias, de las ciudades de Ottawa y Hull y de otras municipalidades de las provincias de Ontario y Quebec distintas de estas últimas ciudades.

Sin entrar en el detalle de las funciones, debe decirse que los objetivos de la National Capital Commission miran a la preparación de planes para el desarrollo, conservación y mejora de la región capital a fin de que su naturaleza y carácter de sede del gobierno del Canadá estén de acuerdo con su significación nacional.

La Comisión está autorizada para construir y mantener parques, plazas, avenidas, puentes, edificios y otras obras, administrar sitios y museos históricos, construir y operar lugares de recreación, y cooperar con los municipios $u$ otras autoridades en el mejoramiento de sus propiedades.

El señor Fullerton (8) agrega un elemento de mucha importancia: la buena localización de las tierras federales, lo cual le da mucho que decir en cuanto a los nuevos desarrollos municipales.

i) Si los intentos de distrito federal no han cristalizado, existe la «región de la capital nacional». Según la ley de 1958, ésta es la sede del Gobierno del Canadá y las áreas que la rodean, y sobre la cual extiende su jurisdicción la National Capital Commission.

Esta región se ha venido formando pragmáticamente a lo largo del tiempo, como se ha visto. El profesor Donald C. Rowat (9) anota

(6) Op. cit., p. 32.

(7) DOUglas H. FUllerton, vol. I, p. 19.

(8) DOUgLaS H. FULLERTON, vol. I, p. 55.

(9) The Government of Federal Capitals, University of Toronto Press, 1973, p. 320. 
que desde 1927, al crearse la Comisión de Mejoramiento de la Capital, Hull fue reconocida como parte integrante de la capital.

Hoy en día, según los datos del documento de la National Capital Commission de 1984 citado en esta ponencia, la región de la capital comprende 466.200 hectáreas y una población de 740.000 habitantes. La mayor parte del territorio y de la población están del costado de Ontario. Dentro de esta última también es más alto el número de personas que hablan inglés que francés.

Pero las ciudades de Ottawa y Hull que sirven de ejes de estas dos porciones de la región de la capital nacional están, a su turno, organizadas como áreas metropolitanas. En 1969 se creó la región municipal Ottawa-Carleton. Ella comprende municipalidades que están hoy completamente incorporadas a la ciudad de Ottawa, y otras en territorios más alejados. Existe un consejo regional representativo y facultades administrativas para fines regionales (planificación, vías, financiación, por ejemplo). Para contrabalancear esta organización, si así puede decirse, por el lado del Quebec se puso en marcha la Outaouais Regional Community, que agrupa más de 30 municipalidades alrededor de Hull.

Esto hace parte de la complejidad del fenómeno municipal que se ha tejido alrededor de Ottawa, en el cual se superponen distintos tipos de autoridades. Es comprensible que la situación indicada aumente las dificultades para el establecimiento del distrito federal.

Naturalmente que no es una complejidad particular a OttawaHull. En Washington se ha observado la necesidad de la articulación del distrito capital con municipios que pertenecen a Estados diferentes. Caracas también tiene la organización de distrito federal y al lado la de área metropolitana con municipios que no hacen parte de él. En ciudad de México es otro tanto.

j) La constitución de un distrito federal en Ottawa-Hull ha sido planteada en distintas ocasiones en el Canadá. Los estudios que se han hecho por comisiones de muy alto nivel durante el presente siglo han tenido la recomendación del distrito federal o la han rechazado.

Un especialista de la materia y quien ha trabajado mucho el tema, el profesor de la Universidad de Carleton (Ottawa), Donald C. Rowart, lo ha propuesto dentro de su libro citado ya, que es un clásico que estudia comparativamente la manera como están organizadas varias capitales federales, con la contribución de profesores de esos países.

Puede decirse que la idea reposa en la dificultad que supone el manejo de una capital por una suma de autoridades concurrentes, la limitación de los poderes de la National Capital Commission, la 
necesidad del gobierno central de dirigir la planeación y el desarrollo de la capital, y el propio examen de lo que sucede en otros países federales.

La alternativa del distrito federal aparece dentro de un conjunto en el cual se analiza también la viabilidad de la ciudad-Estado (la undécima provincia del Canadá, como se ha dicho); ésta es la forma jurídica que ha adquirido Viena, la capital de Austria; otra es la de la ciudad sometida a las normas de un Estado parte de una federación.

Este sería el caso de Ottawa, dentro de la provincia de Ontario, o de Hull, dentro de la de Quebec. Pero las circunstancias que agravan los problemas de la capital canadiense provienen justamente de que de ella hacen parte dos ciudades pertenecientes a diferentes provincias, y con lenguas y culturas distintas.

La propuesta del profesor Donald C. Rowat, que aparece también en forma extensa en otro sitio (10), hace la réplica a la creencia de que distrito federal significa pérdida de los derechos políticos de sus habitantes para elegir sus autoridades. Esta circunstancia, que se suele esgrimir como argumento contra su creación, se origina en factores políticos propios de la ciudad de Washington, aunque se da también en otras capitales como Ciudad de México, y está en vía de corrección.

k) Por último, el estudio del antiguo Director de la National Capital Commission, Douglas H. Fullerton, concluye examinando las posibilidades del mantenimiento del statu quo, el distrito federal y la organización de autoridades de diferente nivel en la región capital, una superior, el Consejo Supra-Regional representativo, y gobiernos regionales elegidos, y subdivisiones de éstos de un tamaño mayor que las unidades que eligen concejales hoy en día en el territorio de la capital nacional.

La preferencia del autor por la última fórmula radica, entre otras razones, en la dificultad de que las provincias hagan cesión de territorios para la capital federal. Este factor, que se dio en Washington y que se ha previsto para la nueva capital Argentina de Viedna, chocaría contra consideraciones políticas y emocionales, especialmente del costado del Quebec, sometido a presiones nacionalistas (11).

(10) DOUglas H. FUllerton, vol. II, p. 391.

(11) Obra citada, vol. I, p. 196. 


\section{LA EVOLUCION ORGANIZATIVA DE BOGOTA (12)}

Es evidente que la evolución de Bogotá, capital de la República de Colombia, difiere mucho de la que se ha trazado de la capital canadiense.

La sola circunstancia de pertenecer la primera al mundo latinoamericano, caracterizado por el vertiginoso crecimiento de sus ciudades, arroja una notable diferencia.

Desde otra perspectiva, la estructura federal del Canadá contrasta con la centralista o unitaria adoptada en Colombia desde 1886, la fecha de su última Constitución. No obstante, aun dentro del esquema centralista, Bogotá operó bajo la forma de un «distrito capital». Esta fórmula la sustrajo de la jurisdicción del Departamento de Cundinamarca, del cual ha sido también su capital. A pesar de que la duración de este modelo de estirpe federalista fue corta, la idea del distrito capital ha seguido siendo ofrecida como alternativa para la organización de la capital colombiana.

En otro ángulo, el otorgamiento en 1945 de la categoría Distrito Especial a Bogotá significó una entrada al tema de las áreas metropolitanas. Este fenómeno se ha presentado en el conjunto Ottawa-Carleton, como ya se indicó. También se observa en los gobiernos regionales que se ha estructurado en torno de OttawaHull. Es este, entonces, un segundo elemento que puede animar una visión comparativa de las dos distantes capitales:

a) Bogotá fue fundada por el conquistador español Gonzalo Jiménez de Quesada en 1538, y acaba de celebrar sus cuatrocientos cincuenta años. Su fundación, a la manera española, significó un pequeño plan urbanístico: trazado de calles, determinación de ciertos edificios públicos, la iglesia principal, servicios de alumbrado y agua, a la usanza de la época.

Bogotá, palabra derivada, como Ottawa, de un vocablo indígena, fue capital del virreinato de Nueva Granada, dentro del régimen colonial. Después de adquirida la independencia en 1810 , también lo fue, y de la Gran Colombia (1821-1830), que forjó la visión de Simón Bolívar al unir las hoy naciones de Venezuela, Ecuador y Colombia. Derrumbado el sueño del Libertador en 1830, Bogotá siguió siendo la capital de la República de Colombia, y así aparece reconocida en la Constitución (art. 199).

(12) Los datos de que aquí se hace uso son tomados de mis libros, Derecho Administrativo, 9. ${ }^{a}$ edición, Temis, Bogotá, 1987, y Temas municipales y regionales, Ediciones Rosaristas, Bogotá, 1985. En este último se encuentran varios ensayos sobre las alternativas de Bogotá, distrito capital, o Bogotá, área metropolitana. 
A diferencia de Ottawa, la suerte institucional de Bogotá se ha buscado definir desde la propia Constitución en varias ocasiones. Quizás sea reflejo del gusto latino de resolver en los textos grandes problemas. Contrasta con el espíritu anglosajón, más amigo de las soluciones prácticas que vienen con los procedimientos, que de las grandes declaraciones.

b) El tránsito del sistema federal de la Constitución de 1863 a la centralista de 1886 implicó que los antiguos Estados miembros de la Federación quedaran convertidos en simples Departamentos. Bogotá, además de ser sede de los poderes nacionales (Congreso de la República, compuesto del Senado y la Cámara de Representantes, Presidencia de la República y Ministerios y Corte Suprema de Justicia), ha sido capital del Departamento de Cundinamarca, en cuyo territorio está enclavada, calidad que todavía tiene.

Su condición de sede de los poderes nacionales era la única diferencia entre Bogotá y las capitales de los otros Departamentos en que está dividido el territorio colombiano.

c) No había transcurrido mucho tiempo desde el retorno al régimen centralista cuando en 1905 surgió una fórmula federalista para la organización de Bogotá: la de distrito capital. Es una curiosidad. histórica, en cuanto que el gobernante bajo cuya inspiración se hicieron las reformas de la estructura territorial era declarado antifederalista: el General Rafael Reyes.

d) El tratamiento de distrito capital dispensado a Bogotá implicó que se la considerara únicamente como sede de los poderes nacionales y dejara de ser capital del Departamento de Cundinamarca, al romper los vínculos con esta organización regional de la cual hasta entonces había hecho parte. De este modo, ya no siguió dependiendo del Departamento en el sistema electoral, ni en su funcionamiento administrativo, y sus finanzas fueron también establecidas de manera separada. El gobierno de la ciudad, entonces, fue confiado al gobierno nacional.

Fue efímero, sin embargo, el carácter de distrito capital. Con la caída del General Reyes, éste desapareció en 1909, y Bogotá se reincorporó para todos los efectos jurídicos al Departamento de Cundinamarca, y volvió a ser su capital, y siguió siendo la sede de los poderes nacionales.

e) Durante la primera mitad del presente siglo el tema de la capital no fue objeto de ninguna modificación constitucional. Se dictaron, sí, leyes sobre Bogotá, sobre sus impuestos y sus funciones, pero más en razón de su crecimiento y de ser la primera ciudad del país que por su condición de capital de la República. Por cierto que el Congreso estableció que estas leyes que había dictado 
inicialmente para Bogotá se extendieran a otras capitales de Departamento o a ciudades de determinada población.

f) Pero en 1945, al discutirse otra reforma constitucional, se planteó que la ciudad quedara nuevamente como distrito capital, como había sido en 1905. Solamente que el Departamento de Cundinamarca tuvo conciencia de lo que le significaba que Bogotá saliera jurídicamente de su territorio. Aparte de razones históricas dignas de consideración, Cundinamarca sin Bogotá dejaba de ser uno de los Departamentos más importantes del país, y en el plano de los recursos, ni los impuestos a los habitantes ni a los consumos de la gran ciudad irian para Cundinamarca, sino que serían haberes propios de la capital.

g) Por esta oposición de la entidad territorial intermedia entre el Estado y el municipio, surgió un concepto de compromiso que llamó a Bogotá ya no distrito capital sino "distrito especial», y la reforma de 1945 confió a la ley la organización político-administrativa de la ciudad.

Esta denominación es, obviamente, fruto de una transacción política. Ella no le da un territorio exclusivo a la capital de la nación, sustraído de otra organización regional; si así puede decirse, se toma la capital del Departamento de Cundinamarca para que sea también la capital de la República. Al no estar separada territorialmente del Departamento, como las otras ciudades, Bogotá hace parte de la organización electoral de Cundinamarca (para la elección de Senadores, miembros de la Cámara de Representantes y Diputados a su Asamblea). Tiene, como todas las otras municipalidades, su propio concejo municipal, y desde el año de 1988 elige su propio Alcalde, que con anterioridad era nombrado por el Presidente de la República (los de las otras capitales del Departamento eran nombrados por los Gobernadores).

Como país centralista, Colombia posee una ley sobre la estructura y las funciones de las municipalidades, aunque se han dictado algunas normas especiales para ciertos municipios o aspectos de la vida municipal. Para Bogotá Distrito Especial existe un estatuto especial, que está consignado en el decreto-ley 3133 de 1968.

Por ese carácter especial de la ciudad capital, Bogotá no está sometida a las reglas administrativas que dicten la Asamblea de Cundinamarca y el Gobernador de este Departamento, como es el caso de las demás capitales regionales. Desde este punto de vista tiene autonomía plena para actuar según lo que acuerde el Concejo Distrital y el Alcalde mayor de la ciudad.

El aspecto de la repartición de las rentas entre el Departamento de Cundinamarca y Bogotá ha tenido mucha importancia; el 
Departamento tiene interés de conservar a la capital de la República dentro de su territorio, puesto que es la ciudad de los más grandes consumos. Si Bogotá, por ejemplo, se convirtiera en distrito capital, como una capital federal, los impuestos que puede recaudar hoy el Departamento de bienes o actividades o consumos situados en ella serían para la ciudad exclusivamente. Este punto, como ya se dijo, y otros adicionales han originado la oposición de Cundinamarca a la fórmula del distrito capital, tal como se vio en 1945. No obstante, la Constitución prevé que una ley puede otorgar a la capital una participación en las rentas departamentales que se causen dentro de su territorio.

h) Comparativamente con Ottawa, Bogotá también se ha querido que sea organizada como distrito federal o, por lo menos, como distrito capital; dado el sistema centralista colombiano, la primera expresión no tendría cabida.

Como en relación con Ottawa-Hull, ha existido una oposición de una entidad territorial superior, por razones muy válidas, que cualquier otro Departamento alegaría si se fuere a sustraer de su territorio su capital (piénsese en la reacción de Antioquía con Medellín, o el Valle con Cali, o Santander con Bucaramanga, para sólo citar algunos ejemplos).

Por lo demás, el desarrollo de Bogotá, como sede de los poderes nacionales, no encuentra obstáculo en las normas departamentales, ya que la ciudad dispone de absoluta autonomía para ordenar su crecimiento. Desde esta perspectiva se entiende bien cómo en un régimen centralista existe menos interés jurídico en "hacer una capital» que en un sistema federal; en este último existe la necesidad, si se quiere, de arrancar la ciudad de uno o varios Estados miembros de la Federación para permitirle ser nacional, o del conjunto. Dentro del centralismo es la ley la que da el marco de organización de los municipios, y esa misma ley, que es nacional, puede darle un estatuto particular a la capital, como ha sido la evolución de Bogotá.

El problema, entonces, de la «capital» es de menos importancia o necesidad en los países centralistas que en los federales. Tal vez no se consiga un libro como el del Profesor Donald C. Rowat que encuentre parámetros o modelos organizativos: la variedad aquí es mayor aún.

i) La evolución jurídica colombiana también parece alejarse de un estatuto singular para Bogotá, diferente del régimen que cubre a las otras ciudades. El funcionamiento del Concejo del Distrito Especial difiere poco del de las demás municipalidades. De otro lado, como ya se advirtió, cuando quiso aumentarse la participación 
política ciudadana con la elección de los Alcaldes, se dispuso en la reforma constitucional de 1986 que el Alcalde de Bogotá también sería elegido. No pasa así en los distritos capitales-federales, generalmente.

Cuando a partir de 1968 se pensó que la condición de Distrito Especial le proporcionaba a Bogotá un régimen jurídico muy diferente del de las otras municipalidades, la Corte Suprema de Justicia, en ejercicio del control de la constitucionalidad de las leyes, determinó que la capital seguía siendo un municipio con ciertas excepciones previstas en la ley, pero sin que ésta pudiera contrariar lo que de la calidad municipal se desprende de la Constitución.

En 1986 se dictó el Código de Régimen Municipal (decretoley 1333), que modificó y actulizó la legislación municipalista, como se había hecho para la relativa a los Departamentos (decretoley 1222 de 1986). El Gobierno, fundado en una opinión a mi juicio errada del Consejo de Estado, guardó silencio en el Código de la materia sobre Bogotá, como si no fuera un municipio. Al hacerlo privó a los habitantes de la capital de la República de mecanismos de participación política y en servicios públicos acordados por la legislación para todos los demás ciudadanos urbanos.

Ahora se ha dictado la ley $9 .^{a}$ de 1989 , que ha opuesto las cosas en su punto al establecer que las disposiciones del Código de Régimen Municipal son aplicables a Bogotá en cuanto no se opongan a las especiales de ella expedidas en 1968. Así se lee en el artículo 125 de la Reforma Urbana: "Toda referencia en la presente ley y en el decreto-ley 1333 de 1986 a los municipios incluirá al Distrito Especial de Bogotá y a la Intendencia de San Andrés y Providencia, salvo en aquello para lo cual éstos tengan un régimen especial.»

O sea, que hasta este momento la solución que pudiéramos denominar federalista, como la del distrito capital que operó de 1905 a 1909, más que verse llegar se distancia.

j) Restaría por examinar el aspecto atinente a Bogotá como área metropolitana. Debo decir que esta perspectiva de la reorganización institucional ha sido menos discutida que la anterior, y de todos modos luce más confusa que aquella de la capital nacional.

Cuando en 1945 a Bogotá se la colocó bajo la forma de «distrito especial», dijo el Constituyente también que se le anexionarían los municipios circunvecinos. Esto quería decir que la multiplicidad de relaciones intermunicipales que se generan por la expansión de las grandes ciudades sobre los municipios vecinos ya se estaban produciendo en el territorio de la Sabana de Bogotá. 
No obstante, sólo hasta 1954 se comenzó a poner en movimiento esa previsión constitucional, sin mucha claridad sobre la solución metropolitana que se estaba aplicando. El paso que se dio fue una autorización del Consejo Administrativo de Cundinamarca (que existía entonces de manera provisional) para que algunos municipios del Departamento fueran anexionados a Bogotá. De esta manera, Usaquén, Engativá, Fontibón, Bosa, Usme y Suba fueron incorporados como simples barrios o vecindarios a la ciudad capital. Si el Departamento de Cundinamarca consintió la cesión territorial, como lo hacen las partes de una Federación al nacer una capital federal, el cercenamiento de los atributos municipales (personalidad jurídica, autoridades propias, autonomía administrativa y patrimonial) implicó una mala experiencia de la fórmula de las áreas metropolitanas. En lugar de la asociación entre la capital metropolitana y los municipios circunvecinos, lo que se produjo fue la eliminación de estos últimos.

Esta operación es aún hoy controvertida, más cuando las comunidades de los llamados «municipios anexionados» saben que el concepto metropolitano les permitiría como municipios elegir sus propias autoridades.

k) Como ya se expresó, la categoría jurídica de áreas metropolitanas fue introducida en la Constitución colombiana de 1968. Pero no bajo esa modalidad de fusión que se puso en marcha equivocadamente en 1945 en Bogotá, sino bajo la que podríamos denominar asociativa. En efecto, el artículo 198 de la Constitución ordena que haya autoridades metropolitanas comunes $y$ que las municipales, que continúan como tales y no desaparecen, participan en esa formación de autoridades comunes.

La ley 61 de 1979 y el decreto-ley 3104 del mismo año señalaron el cuadro dentro del cual deben configurarse las áreas metropolitanas. Se han organizado con posterioridad las situadas en torno a las grandes capitales departamentales de Medellín, Cali, Barranquilla y Bucaramanga, y una particular alrededor de la ciudad de Pereira.

Pero la indefinición sobre el significado jurídico de Distrito Especial de Bogotá hizo que la capital nacional quedara por fuera del estatuto de las áreas metropolitanas.

Es curioso observar que el régimen de favor que la ley ha querido dar a Bogotá hubiera sido interpretado, a la postre, en contra suya, bien para no permitirle la expansión que regula la figura de las áreas metropolitanas, bien para que sus habitantes fueran privados de derechos que tenían los de los municipios vecinos.

Ahora, en virtud de lo previsto en la ley $9 .^{\circ}$ de 1989 , que contempló la aplicación a Bogotá de las normas del Código de 
Régimen Municipal que no riñan con su estatuto especial, será más fácil la organización del área metropolitana de la Sabana de Bogotá, como se llama el entorno de la capital.

I) Debo concluir diciendo que éste es el problema mayor que tiene la ciudad capital. Ya no se trata simplemente de superar prejuicios jurídicos que se han levantado. como obstáculos en el pasado reciente, sino de que el crecimiento armónico de la ciudad no puede obtenerse sin considerar el espacio que la rodea, que pertenece ya a otros municipios.

Oposición no debe existir del Departamento de Cundinamarca, como él ha hecho con razón a la idea del distrito capital, porque los municipios que ingresarían al área metropolitana con Bogotá no saldrían de su territorio. Tampoco la ha habido de las provincias de Ontario y Quebec, que han dispuesto el funcionamiento de áreas metropolitanas alrededor de Ottawa y Hull.

Sólo que en Colombia el precedente de la absorción por el Distrito Especial de los municipios circunvecinos en 1954 ha suscitado muchos temores en los que ahora deberían hacer parte del área metropolitana del centro del país. Sin embargo, estos últimos están siendo invadidos por la ciudad gigante de cuatro y medio millones de habitantes que tiene Bogotá hoy en día. Por ello es mejor regularizar las relaciones que soportar las que la capital les va imponiendo con un crecimiento desordenado. 